\section{Effects of alkali treatment on modification of the Pinus fibers}

\author{
Renan Zunta Raia ${ }^{1}$, Setsuo Iwakiri ${ }^{1}$, \\ Rosilani Trianoski ${ }^{1}$, Alan Sulato de Andrade ${ }^{2}$, \\ Edemir Luiz Kowalski ${ }^{3}$
}

\author{
${ }^{1}$ Wood Based Panel Laboratory - DETF/UFPR, Av. Prefeito Lothário Meissner, 632, Jardim Botanico, CEP: 80210-170, \\ Curitiba, PR, Brasil \\ ${ }^{2}$ Wood Chemistry Laboratory - DETF/UFPR, Av. Prefeito Lothário Meissner, 632, Jardim Botânico, CEP: 80210-170, \\ Curitiba, PR, Brasil \\ ${ }^{3}$ LACTEC - Rodovia BR-116, Km 98, n. 8813, Jardim das Américas, CEP: 81531-980, Curitiba, PR, Brasil \\ e-mail: renanraia@gmail.com; setuso.ufpr@gmail.com; rosillani@gmail.com; alansulato@gmail.com; \\ edemir@lactec.org.br
}

\section{ABSTRACT}

The aim of this study was to evaluate the effect of the alkalization with different concentrations and time combination in the modification of lignin, hemicellulose and cellulose in pine fibers and determine the best combination aiming the incorporation in plant-based composites. The alkalization process was conducted with 5 concentrations $(5,10,15,20$, and $30 \%$ ) and 2 exposure times ( 2 and 24 hours). Chemical analysis was performed, and cellulose crystallinity, thermal stability, and surface modification were analyzed for the treated fibers. The results showed that there was a reduction in crystallinity with cellulose I - II transformation. Thereafter, the thermal stability and surface characteristics were increased with the increase of the $\mathrm{NaOH}$ concentration. Although all treatments altered the fiber properties, the condition that resulted in technical gain was the condition with $5 \%$ concentration and 2 hours of alkalization. Thus, we can conclude that this condition changes the macromolecular structure of the wood fibers, change the surface and the treat fiber could be used as filler to plant-base composite.

Keywords: Lignocellulosic fibers; Alkalization; Thermal stability; Cellulose crystallinity; Macromolecules.

\section{INTRODUÇÃO}

Lignocellulosic fibers are incorporated into several manufactured products, e.g., furniture, automotive parts, sports equipment, plant-based composites, due to their low cost, biodegradability, high quality, and physical properties [1].

Several fibrous species can be technically used as plant-based composites, such as jute, sisal, pineapple leaf, and wood fibers. Among the main advantages of hybrid composites are the reduction in the density of the product, lower cost, and greater flexibility, and the product is eco-friendly [2].

The main negative effect of plant-based composites production is the incompatibility between the fibers (hydrophilic) and the polymer matrix (hydrophobic), which affects the adhesion between both components [3, 4]. This interaction can be modified with superficial or structural fiber treatment, such as acetylation, bleaching, and alkalization, which may influence the moisture content, the tensile strength of the fibers and can change the chemical composition of fibers, change the polarity and the thermal properties [5-8].

Alkaline treatment is a low-cost method of fiber modification, increasing the compatibility fibers and matrix [9]. This treatment is called mercerization or alkalization and consists of immersing fibers in some alkaline solution, usually sodium hydroxide.

Alkalization conducted in room temperature have many advantages such as low cost of application, simplicity and the treatment can be easily carried out in large scale compared with the high temperature treatment [36].

As a result, alkalization changes the fiber polarity, eliminates surface impurities, decreasing the aggregation of the fibers, remove considerably removes the amount of lignin and less hemicellulose and causes transformation of the cellulose crystallinity [12]. Consequently, alkalization allows for a better response to chemical modification, such as acetylation [9].

Alkalization has long been used as a method of lignocellulosic fiber chemical modification to reinforce plant-based 
composites and it has been the subject of many researchers in many species. Authors have studied alkalization in various species, such as sisal [13], Luffa fiber [14], pineapple leaf fibers [15], hemp [10], jute [2], cashew tree wood flour [16], and bamboo fiber [17], with different $\mathrm{NaOH}$ concentrations, times, and exposure temperatures.

It was proven that alkalization was very effective in improving the characteristics of fiber adhesion in composites by removing the hydrophilic constituents in the fiber, allowing for better matrix bonding, leading to better mechanical properties $[18,19]$.

In this research, Pinus fibers were subjected to alkalization in 5 concentrations of $\mathrm{NaOH}$ and two times. The objective was to evaluate the best concentration and time combination, through qualitative analysis, aiming for later use in the manufacture of plant-based composites.

\section{MATERIALS AND METHODS}

\subsection{Materials}

Pinus fibers from the panels industry were used for alkalization with $\mathrm{NaOH}$ (Analytical Product). $\mathrm{KBr}$ is used in Infrared spectroscopy analyses.

\subsection{Chemical Treatment}

Fibers were dried in an oven at $60^{\circ} \mathrm{C}$ for 48 hours. They were immersed in a sodium hydroxide solution of the following different concentrations: 5, 10, 15, 20, and 30\%. The fibers were alkalized for 2 and 24 hours, as shown in Table 1.

Table 1: Components and condition of treatment of the fibers.

\begin{tabular}{ccc}
\hline TREATMENT & TIME OF EXPOSURE (h) & CONCENTRATION OF NaOH (\%) \\
\hline Control & 0 & 0 \\
$2 \mathrm{~h} 5 \%$ & 2 & 5 \\
$2 \mathrm{~h} 10 \%$ & 2 & 10 \\
$2 \mathrm{~h} 15 \%$ & 2 & 25 \\
$2 \mathrm{~h} 20 \%$ & 2 & 20 \\
$2 \mathrm{~h} 30 \%$ & 2 & 30 \\
$24 \mathrm{~h} 5 \%$ & 24 & 5 \\
$24 \mathrm{~h} 10 \%$ & 24 & 20 \\
$24 \mathrm{~h} 15 \%$ & 24 & 10 \\
$24 \mathrm{~h} 20 \%$ & 24 & 20 \\
$24 \mathrm{~h} 30 \%$ & 24 & 30 \\
\hline
\end{tabular}

Then, the fibers were washed several times with tap water to clean the fibers and eliminated the $\mathrm{NaOH}$ on the surface. Then, the fibers were dried in an oven $\left(60^{\circ} \mathrm{C}\right)$ to remove free water.

\subsection{Wide-Angle X-Ray Diffraction}

For these analyses is used the SHIMADZU XRD-7000 X-ray diffraction equipment

WAXRD tests were performed to study the cellulose crystallinity index of the fibers. Both treated and untreated fibers were milled and then tested, using $40 \mathrm{kV}$ with $20 \mathrm{~mA}$ and angular variation from $5^{\circ}<2 \theta<35^{\circ}$. The velocity was $1 \%$ min using $\mathrm{Cu}-\mathrm{K} \alpha$ radiation.

The cellulose crystallinity was determined by the Segal method [20], which was obtained from the difference between the maximum diffraction intensity (crystalline region) and the minimum diffraction intensity (amorphous region), through equation 1 .

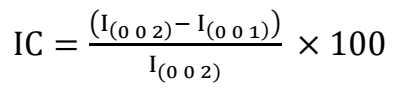

\subsection{Thermogravimetric Analysis (TGA)}

For TGA analyses is used the Setaram Setsys Evolution TGA-DTA/DSC 1500 equipment. 
TGA was carried out to characterize the weight loss of the fibers (treated and untreated) with respect to temperature and to determine the thermal stability of the fibers. TGA was conducted with the following conditions: alumina crucibles, temperature constant at $30^{\circ} \mathrm{C}$ for $10 \mathrm{~min}$, heating from 30 to $650{ }^{\circ} \mathrm{C}$ at a rate of $15^{\circ} \mathrm{C} / \mathrm{min}$, and cooling from 650 to $30^{\circ} \mathrm{C}$ at a rate of $30^{\circ} \mathrm{C} / \mathrm{min}$, with an argon flux of $20 \mathrm{~mL} / \mathrm{min}$.

\subsection{Fourier Transform Infrared Spectroscopy (FTIR)}

For FTIR analyses is used the BRUKER Vertex 70 equipment.

Infrared spectroscopy was carried out to identify the type of bonding and the components present in the fibers.

The fibers (treated and untreated) were milled and mixed with $\mathrm{KBr}$ (potassium bromide) and a thin pellet was made with a mechanical press. Scanning was performed by transmittance using a wavelength range from 400 at $4000 \mathrm{~cm}^{-1}$ at a resolution of $2 \mathrm{~cm}^{-1}$, and the spectrum was captured at a rate of 32 scans per minute.

\subsection{Scanning Electron Microscopy}

To obtain the SEM images we used JEOL JSM 6360-LV equipment.

Scanning electron microscopy (SEM) was used to evaluate the morphological characteristics, such as surfaces change, through the $\mathrm{NaOH}$ concentration and exposure time. Before SEM evaluation, the samples were coated with a thin layer of gold $(\mathrm{Au})$ via sputtering for $90 \mathrm{~s}$ with $30 \mathrm{~mA}$ current.

\section{RESULTS AND DISCUSSION}

\subsection{Wide-Angle X-Ray Diffraction}

The X-ray diffractograms of treated and untreated fibers are shown in Figure 1. Two accentuated peaks were found in some treatments, while in others the peaks were slightly accentuated. The first peak was found to range from $15.36^{\circ}$ to $15.68^{\circ}$ in treatment $24 \mathrm{~h} 15 \%$ and $2 \mathrm{~h} 30 \%$, respectively, and the second was found at $21.38^{\circ}$ in treatment $2 \mathrm{~h} 30 \%$ and 23.04 ${ }^{\circ}$ in treatment $24 \mathrm{~h} 5 \%$. The peak at about $16^{\circ}$ is usually attributed to the accumulation of the (ll 010 ) plane of amorphous constituents, and the second peak at about $22^{\circ}\left(\begin{array}{lll}0 & 0 & 2\end{array}\right)$ is usually attributed to the presence of the crystalline region of cellulose.

By analyzing Figure 1, it was noted that there was transformation of Cellulose-I to Cellulose-II, but not a complete transformation. This happened because the cellulose structure did not swell enough, and the structure remained in the Cellulose-I form [21]. The higher concentration treatment caused a decrease in crystallinity, consistent with the reduction of the crystallinity peak ( $\left.\begin{array}{lll}0 & 0\end{array}\right)$, probably due to the amorphization of the fiber [22].
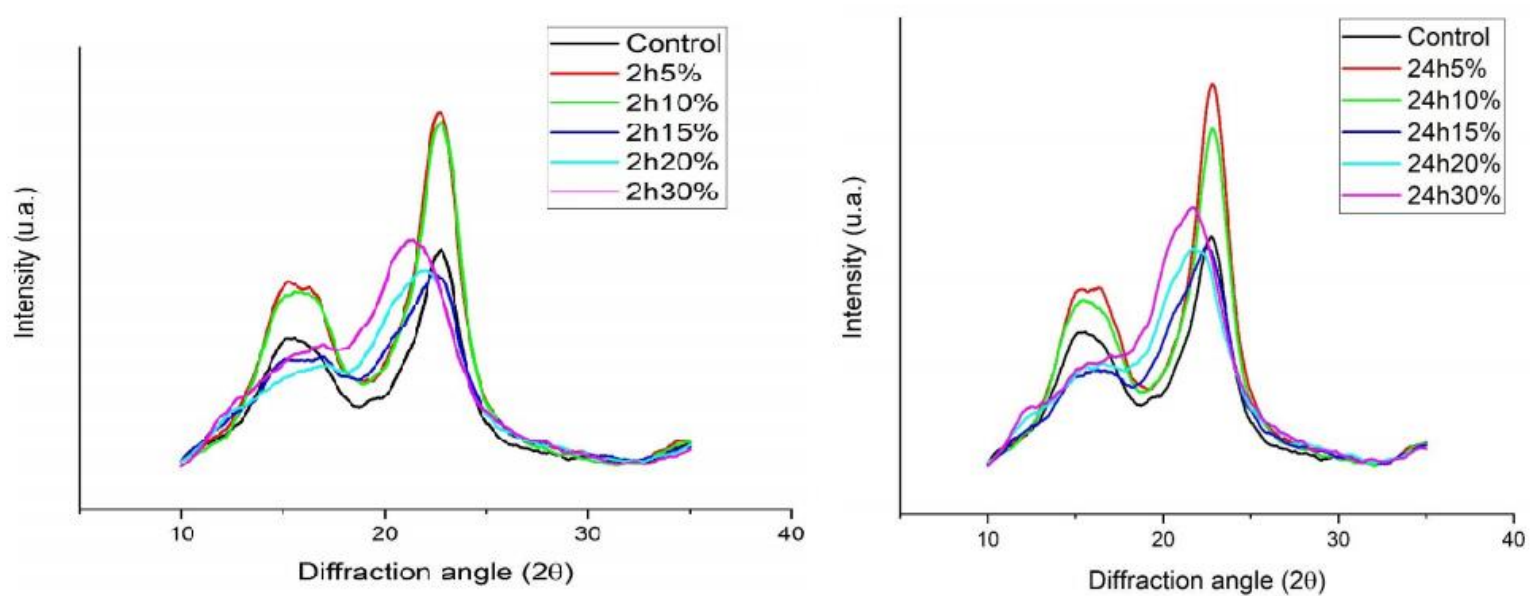

Figure 1: X-ray diffraction of treated and untreated fiber.

The crystallinity index (CI) obtained by equation (2) is presented in the Table 2 . An increase in the CI for treated fibers, in less concentration of $\mathrm{NaOH}$ for both time, was observed in relation to the control due to the removal of excess amorphous regions on the fibers, such as lignin, hemicelluloses, and the amorphous region of cellulose, however, the excessive concentration of $\mathrm{NaOH}$ and time caused a decrease in the $\mathrm{CI}$, indicating that the occurs the deterioration of the exposed cellulose, causing the decrease of the crystallinity [23]. Treatment $24 \mathrm{~h} 5 \%$ showed the highest result for the CI, 
with a value of $69.73 \%$ and this can be explained by the fact that the exposure time influences the elimination of lignin and hemicellulose.

Table 2: Crystallinity Index of treat and untreated fibers.

\begin{tabular}{cccc}
\hline TREATMENT & INTENSITY (0 0 2) & INTENSITY (0 0 1) & CRYSTALLINITY (\%) \\
\hline Control & 665 & 266 & 60,00 \\
$2 \mathrm{~h} 5 \%$ & 984 & 324 & 67,07 \\
$2 \mathrm{~h} 10 \%$ & 982 & 346 & 64,77 \\
$2 \mathrm{~h} 15 \%$ & 606 & 293 & 51,65 \\
$2 \mathrm{~h} 20 \%$ & 614 & 335 & 45,44 \\
$2 \mathrm{~h} 30 \%$ & 716 & 395 & 44,83 \\
$24 \mathrm{~h} 5 \%$ & 978 & 296 & 69,73 \\
$24 \mathrm{~h} 10 \%$ & 954 & 299 & 68,66 \\
$24 \mathrm{~h} 15 \%$ & 666 & 219 & 67,12 \\
$24 \mathrm{~h} 20 \%$ & 648 & 259 & 60,03 \\
$24 \mathrm{~h} 30 \%$ & 778 & 416 & 46,53 \\
\hline
\end{tabular}

According to Mwaikambo and Ansell [10], high crystallinity is likely to result in stiff, strong fibers, which is interesting in the formation of lignocellulosic fiber composites. However, at higher $\mathrm{NaOH}$ concentrations the crystallinity decreases in relation of the lower concentrations, indicating that a low concentration of $\mathrm{NaOH}$ has a positive effect on fiber crystallinity due to the elimination of waxes, lignin, and hemicelluloses, contributing in the interfacial compatibility between the fiber and the matrix.

The greater crystallinity in the $24 \mathrm{~h}$ exposure time, can be explained due to the leaching of more and more hemicellulose and lignin occurs during the alkalization time, which causes a greater crystallinity of the cellulose. This does not happen in the $2 \mathrm{~h}$ period, since the alkali action time is short to cause a great deterioration of the cementing agents and with this there is less crystallinity.

The same characteristic found in this research, it found for other researchers for wood, cotton, Agave americana L. and Tridax procumbens [12, 24-26].

\subsection{Thermogravimetric Analyzes}

Thermal stability is one of the most important properties because the interfacial thermal resistance between the matrix and the fibers can influence the processing and service life performance of the composites [27, 28].

TGA was carried out on treated and untreated fibers, and the results can be seen in Figure 2. The thermal decomposition of the fibers (treated and untreated) occurred in two stages, which is reflected by the two peaks in the DTG curve. The first peak occurred between 30 and $120^{\circ} \mathrm{C}$, which was due to the loss of water present in the fibers, and it is responsible for the slight loss of fiber mass. The second step started at $150{ }^{\circ} \mathrm{C}$ and finished at around $450^{\circ} \mathrm{C}$ and was due to the decomposition of the lignocellulosic material. This step can be divided in three stages: first, the hemicelluloses, waxes, and extractives degrade $\left(150\right.$ to $\left.300{ }^{\circ} \mathrm{C}\right)$; then, the cellulose $\left(300\right.$ to $\left.350^{\circ} \mathrm{C}\right)$. Lignin has a slow and long thermal degradation occurring throughout the degradation process of lignocellulosic compounds, starts with the first compounds and end before the cellulose degradation [29].

From Table 3, it is seen that the percentage of residues varied from 32.21 to $36.90 \%$, which can be explained by the difference in the amount of volatile materials and ash present in the treated fibers [30].

The onset temperature increased in relation to the control. This can be explained by the reduction of the concentration of the extractive and lignin, which was caused by the alkali treatment. The extractives include pectin, waxes, and natural resins, which are compounds that have degradation temperatures lower than cellulose. Alkali treatment increases the average size of the fibers, decreasing the superficial area. Therefore, higher specific energy is needed to degrade the fibers [16]. We can infer that the treatment tends to degrade the segments less molecular and with that the just the major structure still in the fibers.

By analyzing the DTG curves, we can infer that the maximum temperature of degradation decreases with the $\mathrm{NaOH}$ concentration increases, which is consistent with the results obtained in the XRD analyses where the crystallinity decreases with the concentration. This is probably due to the decrease in the amorphous parts of fibers and the low degree 
of polymerization components of the fiber, such as lignin, hemicelluloses, and specific regions of the cellulose.

In Table 3, it can be observed that the higher onset temperature was reached in the treatment $2 \mathrm{~h} 5 \%$. This is a good technical result because this treatment was proven to be the most thermally stable, even when using the lowest concentration of reagent, thus decreasing the cost and improving the environmental question on the alkalization, therefore we can infer that these treatment has the best cost benefit.

The improved thermal stability of the treated fibers is likely to be due to thermally unstable compounds (hemicellulose and pectin) being removed after the alkalization [36], with more removal occurring in lower concentration compared to higher alkali concentration as supported by FTIR analysis.

When we analyze the exposure time in thermal stability, it is possible to see that the 24 hours of exposure tends to present lower endset temperature, this occurs because the longer exposure time removes more hemicellulose, pectin and lignin causing a negative influence on thermal stability, which corroborates the result found in XRD.

Table 3: Summary of main thermal properties of treated and untreated Pinus fibers.

\begin{tabular}{llll}
\hline \multicolumn{1}{r}{ TREATMENT } & \% RESIDUES & T C ONSET & T oC ENDSET \\
\hline Control & 33,92 & 270,7 & 386,8 \\
$2 \mathrm{~h} 5 \%$ & 36,51 & 283,9 & 380,0 \\
$2 \mathrm{~h} 10 \%$ & 33,00 & 280,8 & 381,0 \\
$2 \mathrm{~h} 15 \%$ & 33,46 & 279,1 & 377,9 \\
$2 \mathrm{~h} 20 \%$ & 276,1 & 375,3 \\
$2 \mathrm{~h} 30 \%$ & 33,33 & 275,8 & 374,5 \\
$24 \mathrm{~h} 5 \%$ & 32,21 & 279,1 & 377,8 \\
$24 \mathrm{~h} 10 \%$ & 34,86 & 281,0 & 286,2 \\
$24 \mathrm{~h} 15 \%$ & 34,25 & 274,1 & 380,0 \\
$24 \mathrm{~h} 20 \%$ & 32,68 & 278,3 & 371,2 \\
$24 \mathrm{~h} 30 \%$ & 34,60 & 280,1 & 374,3 \\
\hline
\end{tabular}
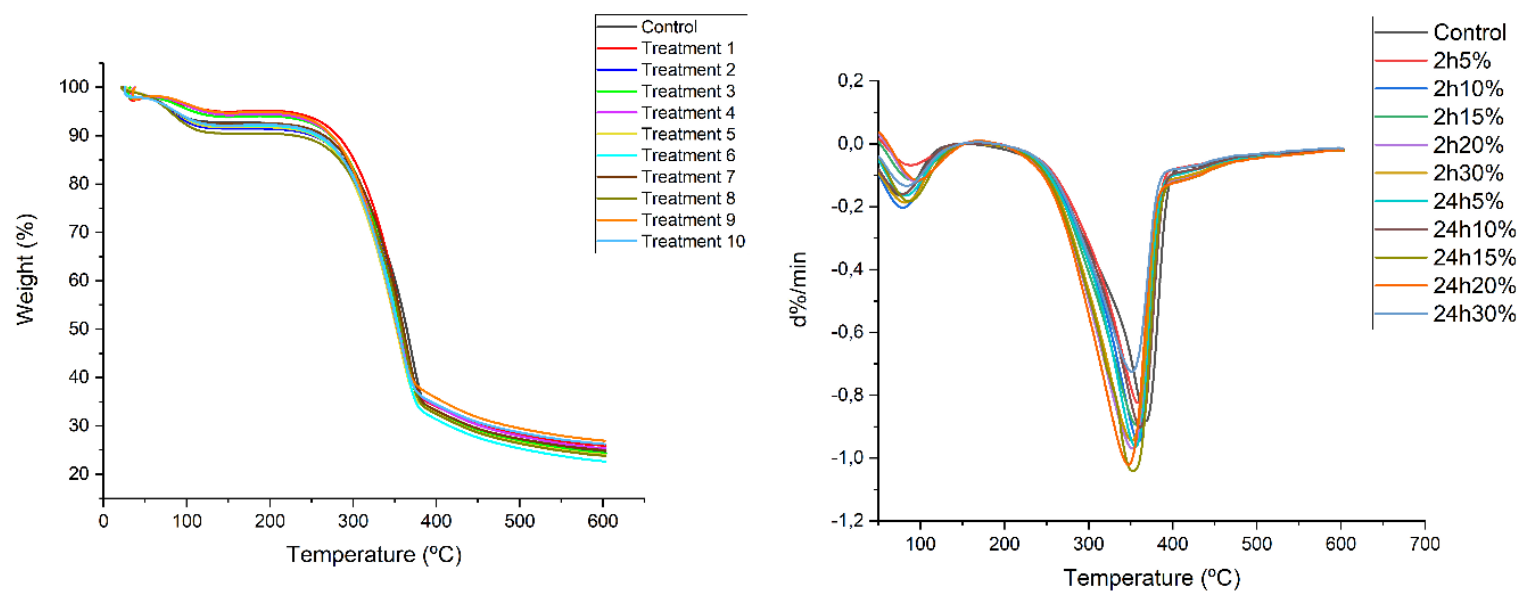

Figure 2: TGA and DTG curves of treated and untreated fibers.

\subsection{Fourier Transform Infrared Spectroscopy}

Figure 3 shows the FTIR spectrums of treated and untreated fibers, with the different peaks between treatment evident.

The stretch around the $3300 \mathrm{~cm}^{-1}$ is characteristic to the presence of the $\alpha$-cellulose, and can be seen in all the treatments, including the control. Is was noted that the peak changes with the concentration/time increase, demonstrating the positive feature of the alkali treatment.

The characteristic peak at round $1734 \mathrm{~cm}^{-1}, 1600 \mathrm{~cm}^{-1}$ and $1200 \mathrm{~cm}^{1}$ relates to the presence of a carbonyl group 
$(\mathrm{C}=\mathrm{O})$ and is attributed to the presence of hemicelluloses and lignin [29]. After observing Figure 3, it can be noted that this peak is only seen in the control. This explain that the alkali treatment remove the hemicelluloses and lignin from the fiber surface with alkali treatment [30]. This observation is striking with the result found in the XRD, which confirms the degradation of lignin and hemicellulose, causing an increase in crystallinity with the concentration.

It can be noted that in the peak $1600 \mathrm{~cm}^{-1}$ and $1200 \mathrm{~cm}^{1}$ still remains a little sharp peak, it can be explained by the fact that there is a partial removal of the lignin, still maintaining an amount that can be seen in these peaks even after the fibers have been treated, but the peak is very smaller that the untreated fibers, it confirmed that the lignin was removed with the alkali treat.

The wavenumber around the $1640 \mathrm{~cm}^{-1}$ was associated with the absorbed water in the crystalline cellulose, and observing the Figure 3, can note that the peak is more intense in the treated fiber than the untreated, this can be explained by the fact that the treatment exposes the cellulose and thus absorbs water with the increase in the concentration of alkali [34]. These effect on the peak $1640 \mathrm{~cm}^{1}$ is similar to time exposure and concentration under the same condition [35]

With the increase in water absorption by the exposed cellulose, it can be inferred that there will be a better compatibility between matrix and filler in the use of these treated fibers in comparison with the untreated fibers.

The effect of treatment time on the peak of $1640 \mathrm{~cm}-1$ under room and elevated temperatures treatment was approximately like the effect of concentration under the same treatment condition

The stretching at $1012 \mathrm{~cm}^{-1}$ and $1017 \mathrm{~cm}^{-1}$, which was due to the presence of alkoxy group $\mathrm{C}=\mathrm{O}$, attributes the hydroxyl and esther groups in cellulose [12].

The second different peak observed in Figure 3 can be seen at around $811 \mathrm{~cm}^{-1}$ in all treated fibers. This peak is related to the presence of sodium $(\mathrm{Na})$ in the surface fibers and can be attributed to the presence of a $\mathrm{Na}-\mathrm{O}$ group. This can explain the presence only in the treated fibers [31,32].

The peak that appears in the $811 \mathrm{~cm}^{-1}$ might be eliminated with a several wash with water and a little hydrochloric acid. In this work, it was only washed with tap water, which may have caused this sharp spike in the treated fibers.

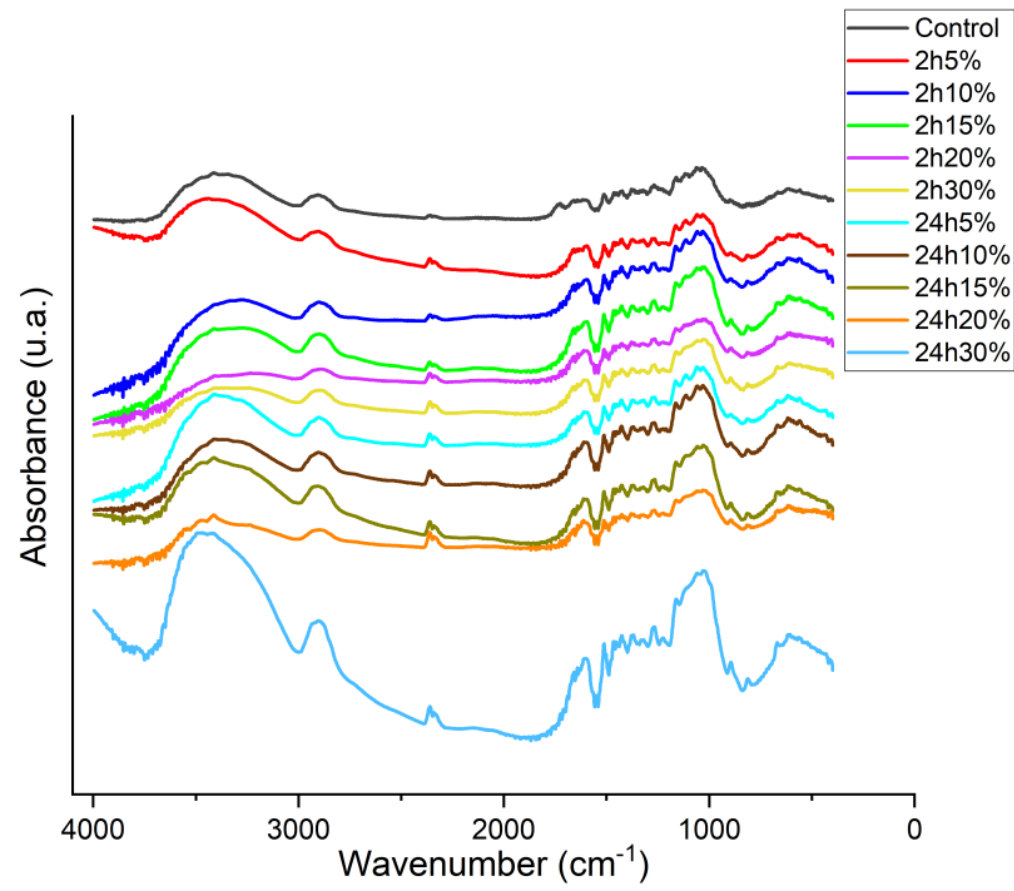

Figure 3: FTIR spectrum of untreated and treated fiber, highlighting the difference between the treatments.

\subsection{Scanning Electron Microscopy}

Although it is a very punctual analysis, SEM can be useful for analyzing the surface of the fibers, as well as impurities, and it can show behavioral tendencies of these with the composite.

Figure 4A shows the untreated fiber. A lot of impurities can be seen on the surface, as well as a waxy appearance due to the presence of wax on the fiber surface.

After alkalization (Figure 4B-K), less impurities on the surface are seen due to leaching. The impurities decrease with increasing the $\mathrm{NaOH}$ concentration (Figure 4B-F, Figure 4G-K), which demonstrates that impurity removal occurs, 
as well as reduction of wax, which can benefit to the interaction between matrix and fibers.

Alkalization caused an increase on the roughness in the surface, inducing better capillary action of the fibers, improving their hygroscopicity and air permeability and increasing the surface area, which can improve the interfacial compatibility between fiber and matrix $[12,33]$.
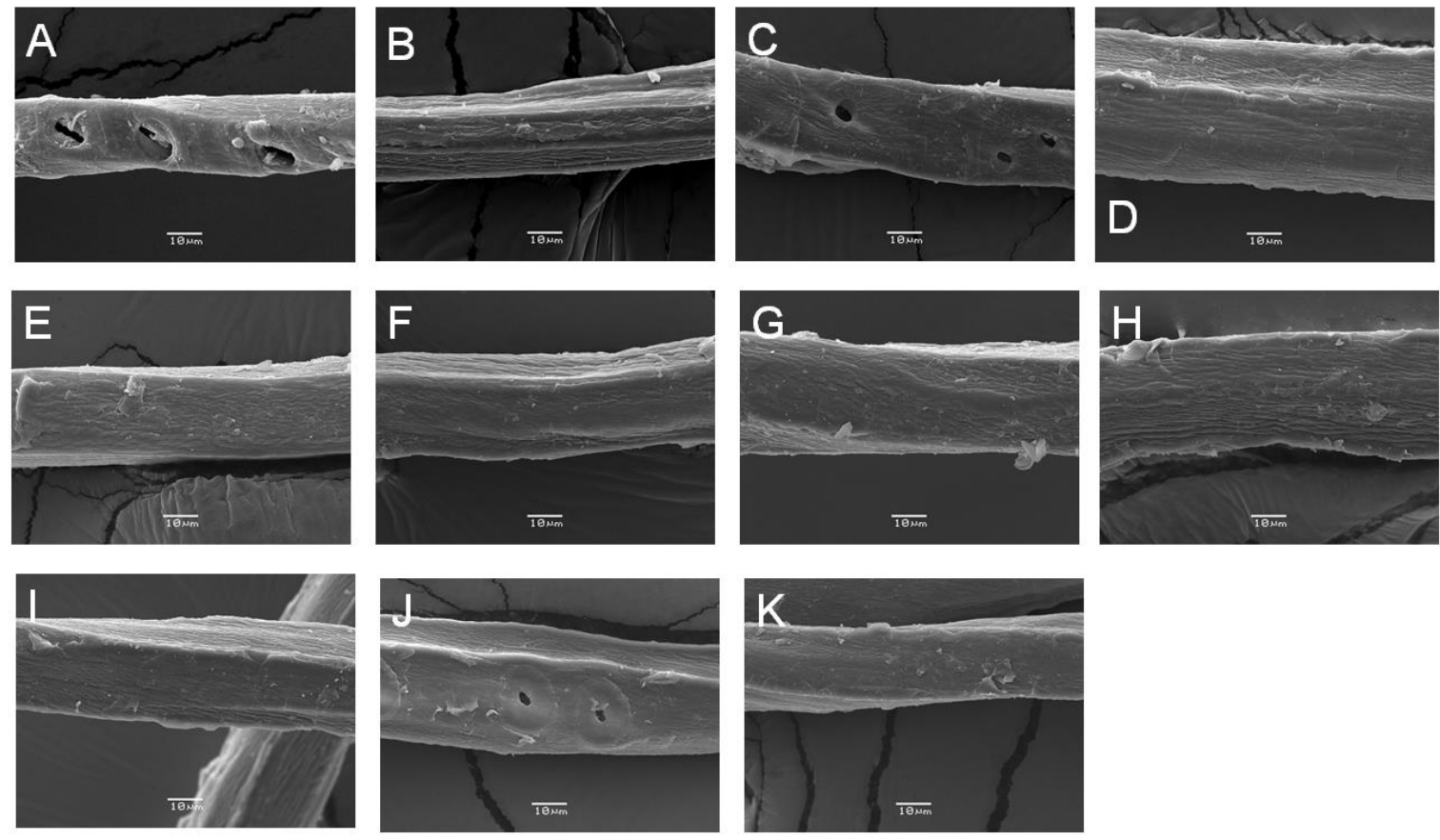

Figure 4: SEM of untreated and treated fibers.

\section{Untreated and (B to K) Treated fibers}

\section{CONCLUSION}

It has been found that alkaline treatment modifies Pinus fibers, thus proving that alkalinization treatment, change the crystallinity, the thermal degradation and a slight transformation to cellulose I into cellulose II. Because of this, alkali treatment can be used by a method of chemical modification of lignin, hemicelluloses and cellulose in wood fibers for applications as fillers in plant-based composites.

Regarding the DRX analyses, we can conclude that the crystallinity increases in the higher concentration of alkali treatment. The higher crystallinity is found on the treatment 1 , due the most reduction of lignin, hemicellulose and impurities of fibers, which can be conclude such as the better treatment for fillers in plant-based composites.

The FTIR verified that there was modification in all treatments, and in the treatment that used $\mathrm{NaOH}$, the characteristic elongation of hemicellulose disappeared and in the higher concentration treatment can be seen the spectrum relation with the transformation of cellulose I into cellulose II. In relation to the surface, it can be concluded that the alkaline treatment decreased the waxy aspect, increased the roughness and decreased the impurities present on the surface, based on SEM images.

The thermal analyzes proved that alkalization using lower concentration and time of exposure, increases the temperature onset, being the treatment $2 \mathrm{~h} 5 \%$ more stable in relation to the others.

Lastly, we can conclude that the treatment $2 \mathrm{~h} 5 \%$ has a higher value for crystallinity and thermal stability in relation to the other and is the most technically feasible alkalization condition for wood fibers modification aiming most various utilization.

\section{ACKNOWLEDGMENT}

The authors thank to Coordenação de Aperfeiçoamento de Pessoal de Nível Superior (CAPES) for funding the research, as well as the anatomy and wood quality, X-Ray optics and instrumentation, Infrared Absorption Spectroscopy and the Electronic Microscopy Center laboratories, all the Federal University of Paraná, for the services provided. 


\section{BIBLIOGRAPHY}

[1] SANJAY, M.R., MADHU, P., JAWAID, M., et al., "Characterization and Properties of Natural Fiber Polymer Composites: A Comprehensive Review", Journal of Cleaner Production., v. 173, pp. 566-581, 2018.

[2] NETO, J.S.S., LIMA, R.A.A., CAVALCANTI, D.K.K., et al., "Effect of Chemical Treatment on the Thermal Properties of Hybrid Natural Fiber-Reinforced Composites", Journal of Applied Polymer Science, v. 136, n. 10, pp. 1-13, 2019.

[3] ROSA, M. F., CHIOU, B. sen, MEDEIROS, E.S., et al., "Effect of Fiber Treatments on Tensile and Thermal Properties of Starch/Ethylene Vinyl Alcohol Copolymers/Coir Biocomposites", Bioresource Technolpogy, v. 100, n. 21, pp. 5196-5202, 2009.

[4] PICKERING, K.L., EFENDY, M.G.A., LE, T.M. "A Review of Recent Developments in Natural Fibre Composites and Their Mechanical Performance", Composites Part A Applied Science Manufactuing, v. 83, pp. 98-112, 2016.

[5] CORRADINI, E., DE MORAIS, L.C., DE ROSA, M.F., et al., "A Preliminary Study for the Use of Natural Fibers as Reinforcement in Starch-Gluten-Glycerol Matrix", Macromololecules Symposia, v. 245246, pp. 558-564, 2006.

[6] KHAN, M.Z., SRIVASTAVA, S.K., GUPTA, M. "Tensile and Flexural Properties of Natural Fiber Reinforced Polymer Composites: A Review", Journal of Reinforced Plastic and Composites., v. 37, n. 24, pp. 1435-1455, 2018.

[7] LIU, Y., MA, Y., YU, J., et al., "Development and Characterization of Alkali Treated Abaca Fiber Reinforced Friction Composites, Compososites Interfaces, v. 6440, pp. 1-16, 2019.

[8] NAVEEN, J., JAWAID, M., AMUTHAKKANNAN, P., et al., Mechanical and Physical Properties of Sisal and Hybrid Sisal Fiber-Reinforced Polymer Composites, 1 ed., Amsterdã, Elsevier Ltd, 2019.

[9] BORYSIAK, S. !Influence of Wood Mercerization on the Crystallization of Polypropylene in Wood/PP Composites!, Journal of Thermal Analysis and Calorimetry, v. 109, n. 2, pp. 595-603, 2012.

[10] MWAIKAMBO, L.Y., ANSELL, M.P. !Chemical Modification of Hemp, Sisal, Jute, and Kapok Fibers by Alkalization!, Journal of Applied Polymer Science, v. 84, n. 12, pp. 2222-2234, 2002.

[11] WERTZ, J., BÉDUÉ, O., MERCIER, J. P. Cellulose Science, 1st ed., Lausanne, EPFL Press, 2010.

[12] VIJAY, R., LENIN SINGARAVELU, D., VINOD, A., et al., "Characterization of Raw and Alkali Treated New Natural Cellulosic Fibers from Tridax Procumbens", International Journal of Biological Macromolecules, v. 125, pp. 99-108, 2019.

[13] JOSEPH, K., THOMAST, S., PAVITHRAN, C. "Effect of Chemical Treatment on the Tensile Properties of Short Sisal Fibre-Reinforced Polyethylene Composites", Polymer, v. 144, n. 23, pp. 32-38, 1996.

[14] QUINAYÁ, D.C.P., D’ALMEIDA, J.R.M. "Nondestructive Characterization of Epoxy Matrix Composites Reinforced with Luffa Lignocellulosic Fibers", Revista Matéria, v. 22, n. 2, 2017.

[15] HUDA, M.S., DRZAL, L.T., MOHANTY, A.K., et al., "Effect of Chemical Modifications of the Pineapple Leaf Fiber Surfaces on the Interfacial and Mechanical Properties of Laminated Biocomposites", Composites Interfaces, v. 15, n. 2-3, pp. 169-191, 2008.

[16] MATTOS, A.L.A., LOMONACO, D., ROSA, M. de F., et al., "Cashew Tree Wood Flour Activated with Cashew Nut Shell Liquid for the Production of Functionalized Composites", Composites Interfaces, v. 25, n. 2, pp. 93-107, 2018.

[17] ZAKIKHANI, P., ZAHARI, R., SULTAN, M.T.H., et al., "Bamboo Fibre Extraction and Its Reinforced Polymer Composite Material", International Journal of Chemical, Molecular, Nuclear, Materials, Metallurgical Enginerring, v. 8, n. 4, pp. 315-318, 2014.

[18] HUNER, U. "Effect of Chemical Surface Treatment on Flax-Reinforced Epoxy Composite", Journal of Natural Fibers, v. 15, v. 6, pp. 808-821, 2018.

[19] SARAVANAKUMAAR, A., SENTHILKUMAR, A., SARAVANAKUMAR, S.S., et al., "Impact of Alkali Treatment on Physico-Chemical, Thermal, Structural and Tensile Properties of Carica Papaya Bark Fibers", International Journal of Polymer Analysis and Characterization, v. 23, n. 6, pp. 529-536, 2018. 
[20] SEGAL, L., CREELY, J.J., MARTIN, A.E., et al., "An Empirical Method for Estimating the Degree of Crystallinity of Native Cellulose Using the X-Ray Diffractometer", Textile Research Journal, v. 29, n. 10, pp. 786-794, 1959.

[21] ABE, K." Novel Fabrication of High-Modulus Cellulose-Based Films by Nanofibrillation under Alkaline Conditions", Carbohydite Polymers, v. 205, pp. 488-491, 2019.

[22] KAHAR, P., TAKU, K., TANAKA, S. "Multiple Effects of Swelling by Sodium Bicarbonate after Delignification on Enzymatic Saccharification of Rice Straw", Journal of Bioscience and Bioengineering, v. 116, n. 6, pp. 725-733, 2013.

[23] REDDY, K.O., REDDY, K.R.N., ZHANG, J., et al., "Effect of Alkali Treatment on the Properties of Century Fiber", Journal of Natural Fibers, v. 10, n. 3, pp. 282-296, 2013.

[24] ISHIKURA, Y., ABE, K., YANO, H. "Bending Properties and Cell Wall Structure of Alkali-Treated Wood", Cellulose, v. 17, n. 1, pp. 47-55, 2010.

[25] GUPTA, P.K., UNIYAL, V., NAITHANI, S. "Polymorphic Transformation of Cellulose i to Cellulose II by Alkali Pretreatment and Urea as an Additive", Carbohydrite Polymers, v. 94, n. 2, pp. 843-849, 2013.

[26] OUDIANI, A.El, CHAABOUNI, Y., MSAHLI, S., et al., "Crystal Transition from Cellulose i to Cellulose II in NaOH Treated Agave Americana L. Fibre", Carbohydrite Poymers, v. 86, n.3, pp, 1221-1229, 2011.

[27] ZHANG, Y., HEO, Y.J., SON, Y.R., et al., "Recent Advanced Thermal Interfacial Materials: A Review of Conducting Mechanisms and Parameters of Carbon Materials", Carbon, v. 142, pp. 445-460, 2019.

[28] JAWAID, M., SAPUAN, S.M., ALOTHMAN, O.Y. Green Biocomposites: Manufacturing and Properties, $1^{\text {st }}$ ed., New York, Springer, 2017.

[29] ALAWAR, A., HAMED, A.M., AL-KAABI, K. "Characterization of Treated Date Palm Tree Fiber as Composite Reinforcement", Composites Part B Engineering, v. 40, n. 7, pp. 601-606, 2009.

[30] SANTOS, J., OLIVEIRA, L., VIEIRA, L., et al., "Eco-Friendly Sodium Bicarbonate Treatment and Its Effect on Epoxy and Polyester Coir Fibre Composites", Construction and Building Materials., v. 21, pp. 417436, 2019.

[31] SGRICCIA, N., HAWLEY, M.C., MISRA, M. "Characterization of Natural Fiber Surfaces and Natural Fiber Composites", Composites Part A Applied Science Manufactuing, v. 39, n. 10, pp. 1632-1637, 2008.

[32] SAYILKAN, H., ERDEMOĞLU, S., ŞENER, Ş., et al., "Surface Modification of Pyrophyllite with Amino Silane Coupling Agent for the Removal of 4-Nitrophenol from Aqueous Solutions", Journal of Colloid and Interface Science, v. 275, n. 2, pp. 530-538, 2004.

[33] GAO, X., LIN, L., PANG, J., et al., "Effects of Impulse-Cyclone Drying and Silane Modification on the Properties of Wood Fiber/HDPE Composite Material", Carbohydrite Polymers., v. 207, pp. 343-351, 2019.

[34] SUGIMAN, S., SETYAWAN, P. D., ANSHARI, B. "Effects of alkali treatment of bamboo fibre under various conditions on the tensile and flexural properties of bamboo fibre/polystyrene-modified unsaturated polyester composites", Journal of Engineering Science and Technology., v. 14, pp. 26-46, 2019.

[35] KIM, H., OKUBO, K., FUJII, T., et al., "Influence of fibre extraction and surface modification on mechanical properties of green composites with bamboo fibre", Journal of Adhesion Sciente and Technology., v. 24, pp. 1348-1358, 2019.

[36] SUNNY, T., PICKERING, K.L., LIM, S.H. "Alkali treatment of hemp for the production of aligned hemp fibre mats for composites reinforcement", Cellulose., v. 27, pp. 2569-2582, 2020.

\section{ORCID}

Renan Zunta Raia https://orcid.org/0000-0002-8775-3763

Setsuo Iwakiri

Rosilani Trianos

Alan Sulato de Andrade

Edemir Luiz Kowalski https://orcid.org/0000-0003-0390-3830

https://orcid.org/0000-0002-3761-6728

https://orcid.org/0000-0003-1574-9623

https://orcid.org/0000-0001-5070-9358 